\title{
Li ion transport in an intercalated polymer electrolyte
}

\author{
N. Arun and S. Vasudevan ${ }^{\text {a) }}$ \\ Department of Inorganic and Physical Chemistry, Indian Institute of Science, Bangalore, India \\ K. V. Ramanathan ${ }^{\text {b) }}$ \\ Sophisticated Instruments Facility, Indian Institute of Science, Bangalore, India
}

\begin{abstract}
Lithium ions solvated by polyethylene-oxide (PEO) have been confined by intercalation within the galleries of an insulating, inorganic layered solid $\mathrm{CdPS}_{3}$. The dc conductivity of this confined polymer electrolyte $\mathrm{Cd}_{0.75} \mathrm{PS}_{3} \mathrm{Li}_{0.5}(\mathrm{PEO})$ displays a distinct change in the mechanism of conduction with temperature, exhibiting a crossover from an Arrhenius temperature dependence at low temperatures to an non-Arrhenius, Vogel-Tamman-Fulcher behavior at higher temperatures. We use ${ }^{2} \mathrm{H},{ }^{7} \mathrm{Li}$, and ${ }^{13} \mathrm{C}$ nuclear magnetic resonance (NMR) in combination with infrared spectroscopy to probe Li ion mobility as well as segmental motion of the intercalated PEO. Within the galleries of $\mathrm{Cd}_{0.75} \mathrm{PS}_{3} \mathrm{Li}_{0.5}(\mathrm{PEO})$ both rigid and mobile fractions of the intercalated polymer are present with the equilibrium fraction of the mobile species increasing with temperature. The ${ }^{7} \mathrm{Li}(I=3 / 2) \mathrm{NMR}$ of the confined polymer electrolyte exhibits an unusual behavior-the appearance of quadrupolar satellites at high temperatures where the conductivity values are appreciable. The results signify the solvation of Li ions by mobile segments of the intercalated PEO. Further proof of this association is seen in the ${ }^{13} \mathrm{C}$ NMR as well as infrared spectra, both of which show evidence of the complexation of $\mathrm{Li}$ ions by ether linkages of the interlamellar PEO at high temperature and the absence of such an association at lower temperature when polymer motion is absent.
\end{abstract}

\section{INTRODUCTION}

Polymers intercalated into low-dimensional host lattices form an attractive class of compounds, ${ }^{1,2}$ since intercalation can combine properties of both the guest polymer and the inorganic host in a single material. These compounds also serve as model systems for understanding the effect of confinement on properties of the guest in relation to those in the bulk. ${ }^{3,4}$ Here we focus on a polymer electrolyte, Lipolyethylene-oxide (Li-PEO), confined by intercalation within the galleries of an inorganic layered host $\mathrm{CdPS}_{3} .{ }^{5}$ The Li-PEO $\mathrm{CdPS}_{3}$-based intercalated polymer electrolyte $\mathrm{Cd}_{0.75} \mathrm{PS}_{3} \mathrm{Li}_{0.5}(\mathrm{PEO})$ has been characterized previously ${ }^{5}$ and a detailed study of the conductivity and dielectric properties reported. ${ }^{6,7}$ Intercalated polymer electrolytes (IPEs) formed by insertion of polyethylene oxide or polypropylene oxide in alkali-ion-exchanged layered solids are of particular significance since the corresponding alkali metal salt dissolved in these polymers, the bulk solid polymer electrolytes (SPEs), are well-known ionic conductors. ${ }^{8}$ The solid polymer electrolytes, because of their potential application in electrochemical devices, have been extensively investigated in the last two decades. ${ }^{9,10}$

Ion conduction in the SPEs is fundamentally different from the conventional ion-hopping conduction observed in solid electrolytes as well as in aqueous or nonaqueous electrolytes. Ionic conductivity in the SPEs is significant only in the elastomeric phase, above the glass transition temperature

\footnotetext{
${ }^{a)}$ Electronic mail: svipc@ipc.iisc.ernet.in

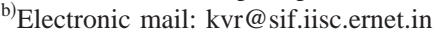

of the polymer. ${ }^{11}$ Alkali ion transport is strongly associated with local polymer segmental motion, as exemplified by the Vogel-Tamman-Fulcher (VTF) form of the temperaturedependent conductivity: ${ }^{12}$

$$
\sigma=\sigma_{0} T^{-1 / 2} \exp \left(-B / T-T_{0}\right) .
$$

In the above equation $T_{0}$ is usually interpreted as an equilibrium glass transition temperature below which all segmental motion is frozen and $B$ the pseudoactivation energy. Further evidence for the role of polymer segmental motion comes from ${ }^{7} \mathrm{Li}$ and ${ }^{1} \mathrm{H}$ nuclear magnetic resonance (NMR) spin lattice relaxation rates, which show a similar temperature dependence, suggesting that the fluctuating fields responsible for the relaxation of the $\mathrm{Li}$ ion and the polymer are the same. ${ }^{13,14}$ Experimental evidence suggests that the mobility of ions in the SPEs is provided by segmental motion of the polymer and that ion transport is largely determined by local dynamics of the solvating polymer. ${ }^{15}$ Knowledge of the structural properties of the ion-conducting amorphous phase is, however, limited and consequently the mechanism of ion conduction, at the molecular level, is still not fully understood.

In PEO- and PPO-based SPEs the alkali ions are solvated by the ether oxygens of the polymer. ${ }^{16-18}$ Structural studies of crystalline PEO complexed with alkali metal salts indicate a crown-ether-like coordination for the alkali ion. These studies, however, are of limited value for predicting properties of the amorphous phase, where ion conduction occurs, since several different structural arrangements which may involve cation-anion pair formation are possible. Although anions are not, generally, solvated, extensive 


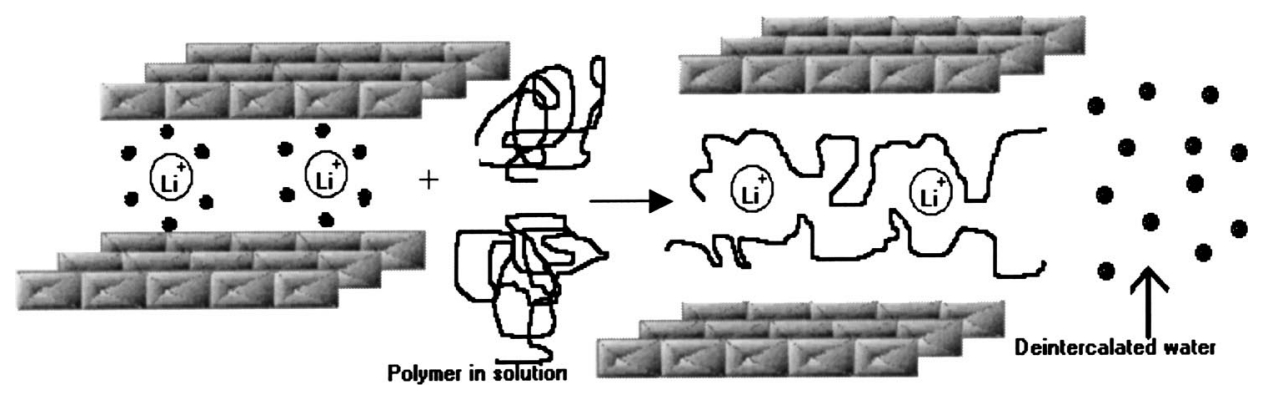

FIG. 1. Drawing illustrating the formation of $\mathrm{Cd}_{0.75} \mathrm{PS}_{3} \mathrm{Li}_{0.5}(\mathrm{PEO})$. Intercalation of uncharged PEO molecules occurs by displacement of the water of hydration of the interlamellar-hydrated $\mathrm{Li}$ ions in $\mathrm{Cd}_{0.75} \mathrm{PS}_{3} \mathrm{Li}_{0.5}\left(\mathrm{H}_{2} \mathrm{O}\right)_{2}$.

polymer-mediated cation-anion pair formation is known to occur because of the relatively low dielectric constant of most polymeric solvents. ${ }^{19}$ Spectroscopic studies ${ }^{20,21}$ have shown that the solvation reaction is complex and that, in addition to fully dissociated ions, ion pairs, triplets, and clusters of varying abundance are present. It is the presence of the several different types of ionic species which contribute, at least in part, to the complexity of the ion transport mechanism. A further complication in the case of PEO-based SPEs is the coexistence of amorphous and crystalline regions. ${ }^{22}$ In the corresponding intercalated polymer electrolyte formed by insertion of PEO into a Li-ion-exchanged layered host (Fig. 1) the massive negatively charged inorganic layer not only provides a confining environment, but also plays the role of the anion. In the metal thiophosphates it has been shown that the negatively charged layers may be treated as insulating sheets of uniform charge density. ${ }^{23}$ The anion as well as anion-Li ion pair contribution to the conductivity may, therefore, be ignored. These are, therefore, ideal systems to probe the association between $\mathrm{Li}$ ion motion and local segmental motion of the polymer.

The intercalated polymer electrolyte $\mathrm{Cd}_{0.75} \mathrm{PS}_{3} \mathrm{Li}_{0.5}$ (PEO) is formed by the complete displacement of water molecules from the hydration shell of interlamellar hydrated $\mathrm{Li}$ ions (Fig. 1) in $\mathrm{Cd}_{0.75} \mathrm{PS}_{3} \mathrm{Li}_{0.5}\left(\mathrm{H}_{2} \mathrm{O}\right)_{2}$ (Ref. 5):

$\mathrm{Cd}_{0.75} \mathrm{PS}_{3} \mathrm{Li}_{0.5}\left(\mathrm{H}_{2} \mathrm{O}\right)_{2}+\mathrm{PEO} \rightarrow \mathrm{Cd}_{0.75} \mathrm{PS}_{3} \mathrm{Li}_{0.5}(\mathrm{PEO})+2 \mathrm{H}_{2} \mathrm{O}$.

Intercalation occurs with a lattice expansion of $8.5 \AA$, and the ratio of the alkali metal to the ether oxygen of the intercalated PEO is 1:3.3. A detailed characterization of the frequency-dependent electrical response in this family of intercalated polymer electrolytes, $\mathrm{Cd}_{0.75} \mathrm{PS}_{3} A_{0.5}(\mathrm{PEO})(A$ $=\mathrm{Li}, \mathrm{Na}, \mathrm{K}, \mathrm{Cs})$ has been reported for a range of PEO molecular weights. ${ }^{6,7}$ At ambient temperatures $\mathrm{Cd}_{0.75} \mathrm{PS}_{3} \mathrm{Li}_{0.5}(\mathrm{PEO})$ exhibits ionic conductivity, comparable to the corresponding SPE, with the conductivity values independent of the molecular weight of the intercalated PEO. The layered host lattice is electrically inert, and hence the conductivity may be attributed entirely to the polymer electrolyte confined within the galleries.

The de conductivity of $\mathrm{Cd}_{0.75} \mathrm{PS}_{3} \mathrm{Li}_{0.5}(\mathrm{PEO})$ shows a change in conduction mechanism with temperature ${ }^{7}$ (Fig. 2). Below $225 \mathrm{~K}$ the dc conductivity values are small and the temperature dependence Arrhenius $\left(E_{a}=2.7 \mathrm{kcal} / \mathrm{mol}\right)$. Above $225 \mathrm{~K}$ the conductivity rises rapidly with temperature and in this regime the temperature dependence is nonArrhenius following the VTF relation with $B=5.9 \mathrm{kcal} / \mathrm{mol}$ and $T_{0}=90.7 \mathrm{~K}$. Although no $T_{g}$ is discernible by differential scanning calorimetry (DSC) measurements, the VTF temperature dependence of the conductivity was considered as evidence for the involvement of segmental motion of the intercalated PEO in ion transport. Support for a possible coupling of ion and polymer motion is the fact that the frequency-dependent electrical response in $\mathrm{Cd}_{0.75} \mathrm{PS}_{3} \mathrm{Li}_{0.5}(\mathrm{PEO})$ showed a single feature-a welldefined conductivity relaxation in the electrical modulus representation-whereas the corresponding dielectric spectra showed no such feature. ${ }^{7}$ In contrast, in intercalated polymer electrolytes in which the conductivity followed an Arrhenius temperature dependence an additional feature- - a dielectric loss due to PEO segmental motion-is seen in the ac electrical response, indicating decoupling of ion motion from polymer segmental relaxation. ${ }^{7}$

Here we report results of a multinuclear NMR spectroscopic study of $\mathrm{Cd}_{0.75} \mathrm{PS}_{3} \mathrm{Li}_{0.5}(\mathrm{PEO})$ as a function of temperature. Multinuclear NMR has been widely used to probe

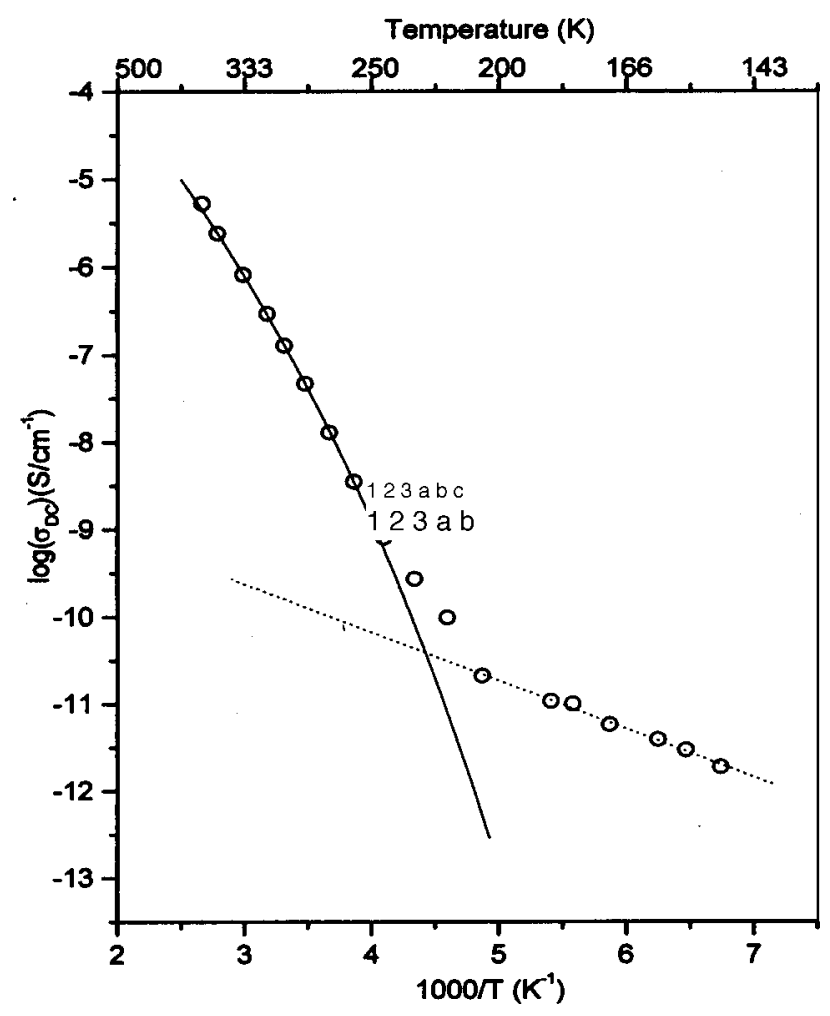

FIG. 2. de conductivity of $\mathrm{Cd}_{0.75} \mathrm{PS}_{3} \mathrm{Li}_{0.5}(\mathrm{PEO})$. The solid line is the fit to the VTF equation (1) and the dotted line the Arrhenius fit (adapted from Ref. $7)$. 
motion of alkali ion in SPEs (Refs. 14, 24, and 25) and also the dynamics in composite polymer electrolytes based on the intercalation of PEO in mica-type silicates. ${ }^{26-28}$ These studies have established that in the SPEs there exist two dynamical regimes: a regime above a temperature $T_{c}\left(T_{c}>T_{g}, T_{g}\right.$ being the glass transition temperature) where ionic motion and polymer segmental motion are coupled and a regime below $T_{c}$ where they are decoupled. In the present study ${ }^{2} \mathrm{H}$ NMR spectroscopy has been used to study local segmental mobility of the interlamellar PEO while ${ }^{7} \mathrm{Li}$ NMR to probe motion and association of the $\mathrm{Li}$ ions. In addition, ${ }^{13} \mathrm{C}$ NMR and infrared spectroscopy have been used to investigate the nature and extent of complexation of the $\mathrm{Li}$ ion by $\mathrm{PEO}$ in the intercalated polymer electrolyte $\mathrm{Cd}_{0.75} \mathrm{PS}_{3} \mathrm{Li}_{0.5}(\mathrm{PEO})$. The present results are able to provide direct spectroscopic evidence for the association of $\mathrm{Li}$ ions with mobile segments of the confined PEO. The results are discussed in the context of the origin of the non-Arrhenius VTF temperature dependence of the $\mathrm{Li}$ ion conductivity reported in this material.

\section{EXPERIMENT}

\section{A. Preparation}

Cadmium thiophosphate was prepared from the elements following the procedure reported in Ref. 29. Cadmium metal powder, phosphorous, and sulphur, in stoichiometric amounts, were sealed in quartz ampoules at $10^{-5}$ Torr and heated at $650^{\circ} \mathrm{C}$ for a period of 2 weeks. The formation of $\mathrm{CdPS}_{3}$ was confirmed by x-ray diffraction (XRD); the pattern could be indexed in the $C 2 / \mathrm{m}$ space group with lattice parameters $a=6.313 \AA, b=10.787 \AA, c=6.906 \AA$, and $\beta$ $=108.35^{\circ}$, similar to that reported in the literature. ${ }^{30}$

The intercalated polymer electrolyte $\mathrm{Cd}_{0.75} \mathrm{PS}_{3} \mathrm{Li}_{0.5}(\mathrm{PEO})$ is formed by the displacement of water molecules in $\mathrm{Cd}_{0.75} \mathrm{PS}_{3} \mathrm{Li}_{0.5}\left(\mathrm{H}_{2} \mathrm{O}\right)_{2}$ by PEO. $\mathrm{A}$ facile route for the preparation of $\mathrm{Cd}_{0.75} \mathrm{PS}_{3} \mathrm{Li}_{0.5}\left(\mathrm{H}_{2} \mathrm{O}\right)_{2}$ is by exchanging the $\mathrm{K}$ ion in $\mathrm{Cd}_{0.75} \mathrm{PS}_{3} \mathrm{~K}_{0.5}\left(\mathrm{H}_{2} \mathrm{O}\right)_{1.2}$ for $\mathrm{Li}$ ions: ${ }^{31}$

$\mathrm{Cd}_{0.75} \mathrm{PS}_{3} \mathrm{~K}_{0.5}\left(\mathrm{H}_{2} \mathrm{O}\right)_{1.2}+\mathrm{Li}_{a q}^{+} \rightarrow \mathrm{Cd}_{0.75} \mathrm{PS}_{3} \mathrm{Li}_{0.5}\left(\mathrm{H}_{2} \mathrm{O}\right)_{2}+\mathrm{K}_{a q}^{+}$.

Ion exchange of the $\mathrm{K}$ ion by $\mathrm{Li}$ ion causes the lattice spacing to increase from 9.4 to $12.2 \AA$ and an increase in the extent of hydration of the interlamellar alkali ion. The potassium-ion-exchanged intercalation compounds were obtained by stirring $\mathrm{CdPS}_{3}$ powder in aqueous solution of $\mathrm{KCl}$ along with a complexing agent EDTA. The $p \mathrm{H}$ of the solution was maintained at 10 using a $1 \mathrm{~mol} \mathrm{~K} \mathrm{CO}_{3} / \mathrm{KHCO}_{3}$ buffer:

$\mathrm{CdPS}_{3}+2 x \mathrm{~K}_{a q}^{+} \rightarrow \mathrm{Cd}_{1-x} \mathrm{PS}_{3} \mathrm{~K}_{2 x}\left(\mathrm{H}_{2} \mathrm{O}\right)_{y} \quad x=0.25 \quad y=1.2$.

Complete ion-exchange intercalation was ascertained by the absence of the host $00 \mathrm{l}$ reflections and the appearance of new $00 l$ reflections with lattice spacing, $9.4 \AA^{4}{ }^{4}$

The intercalation of PEO in $\mathrm{Cd}_{0.75} \mathrm{PS}_{3} \mathrm{Li}_{0.5}\left(\mathrm{H}_{2} \mathrm{O}\right)_{2}$ was carried out by refluxing the lithium-ion-exchanged intercalation compound $\mathrm{Cd}_{0.75} \mathrm{PS}_{3} \mathrm{Li}_{0.5}\left(\mathrm{H}_{2} \mathrm{O}\right)_{2}$ with a methanolic solution of PEO [molecular weight $\left(M_{w}\right)=6 \times 10^{5}$ ] following the procedure reported in Ref. 5:

$\mathrm{Cd}_{0.75} \mathrm{PS}_{3} \mathrm{Li}_{0.5}\left(\mathrm{H}_{2} \mathrm{O}\right)_{2}+\left(\mathrm{CH}_{2}-\mathrm{CH}_{2}-\mathrm{O}\right)_{n}$

$$
\stackrel{\mathrm{MeOH}}{\rightarrow} \mathrm{Cd}_{0.75} \mathrm{PS}_{3} \mathrm{Li}_{0.5}\left(\mathrm{CH}_{2}-\mathrm{CH}_{2}-\mathrm{O}\right)_{2} \text {. }
$$

The intercalation reaction was carried out using Schlenk techniques. $\mathrm{Cd}_{0.75} \mathrm{PS}_{3} \mathrm{Li}_{0.5}\left(\mathrm{H}_{2} \mathrm{O}\right)_{2}$ was refluxed with a methanolic solution of PEO $\left(M_{w}=6 \times 10^{5}\right)$ in a two-necked round-bottomed flask fitted with a rubber septum. The progress of the reaction was monitored by the appearance of a new $00 l$ reflection with $d=15.1 \AA$ in the powder XRD. Completion of the reaction was ascertained by the absence of the $\mathrm{Cd}_{0.75} \mathrm{PS}_{3} \mathrm{Li}_{0.5}\left(\mathrm{H}_{2} \mathrm{O}\right)_{2}$ reflections in the XRD and also by the absence of interlamellar $\mathrm{H}_{2} \mathrm{O}$ using infrared spectroscopy. ${ }^{5}$ The powder was filtered and washed with dry methanol to remove PEO adsorbed on the surface of the crystallites. The intercalation of the deuterated PEO followed an identical procedure.

\section{B. Measurements}

Static ${ }^{2} \mathrm{H}, \quad{ }^{7} \mathrm{Li}$, and ${ }^{13} \mathrm{C}$ NMR spectra of $\mathrm{Cd}_{0.75} \mathrm{PS}_{3} \mathrm{Li}_{0.5}$ (PEO) were recorded on a Bruker DSX-300 solid-state Fourier-transformed NMR spectrometer at Larmor frequencies of 46.07, 116.4, and $75.47 \mathrm{MHz}$, respectively. Temperature variation studies were done using the Bruker variable-temperature accessory (B-VT 2000). The ${ }^{2} \mathrm{H}$ NMR spectra were recorded with typically a 5-s delay between scans. As the spectra in the temperature range 280$330 \mathrm{~K}$ have contributions from mobile and rigid polymer fractions, the spectra were also recorded with longer delays. However, no changes in the spectral pattern and the relative intensities were observed. The significance of these results is discussed in detail in the Results section. The ${ }^{2} \mathrm{H}$ and ${ }^{7} \mathrm{Li}$ NMR spectra were recorded as free-induction decays (FIDs) following $\pi / 2$ pulses and also as echoes following the solid echo pulse sequence; the line shapes for both methods were essentially the same. ${ }^{13} \mathrm{C}$ spectra of static samples of $\mathrm{Cd}_{0.75} \mathrm{PS}_{3} \mathrm{Li}_{0.5}(\mathrm{PEO})$ were recorded by the cross-polarization technique with a contact time of $1 \mathrm{~ms}$ and a repetition time of $5 \mathrm{~s}$.

Infrared spectra of $\mathrm{Cd}_{0.75} \mathrm{PS}_{3} \mathrm{Li}_{0.5}(\mathrm{PEO})$ were recorded in the transmission mode in the spectral range 400-4000 $\mathrm{cm}^{-1}$ on a Bruker IFS55 spectrometer. The samples were pelletized and mounted on a hollow copper block and cooled using a CTI-Cryogenics closed-cycle cryostat. Sample temperature could be varied from 300 to $40 \mathrm{~K}$. The cryostat was evacuated at $10^{-2}$ Torr to prevent condensation on the pellet.

\section{RESULTS AND DISCUSSION}

\section{A. ${ }^{2} \mathrm{H}$ NMR and the mobility of intercalated PEO}

Deuterium NMR has been used to probe the motion of the intercalated $\mathrm{PEO}$ in $\mathrm{Cd}_{0.75} \mathrm{PS}_{3} \mathrm{Li}_{0.5}\left(\mathrm{PEO}-{ }^{2} \mathrm{H}\right)$. The ${ }^{2} \mathrm{H}$ NMR spectra of $\mathrm{Cd}_{0.75} \mathrm{PS}_{3} \mathrm{Li}_{0.5}\left(\mathrm{PEO}-{ }^{2} \mathrm{H}\right)$ at different temperatures is shown in Fig. 3(a). At the lowest temperature $(250 \mathrm{~K})$ the spectrum corresponds to a static quadrupolar powder pattern characteristic for a spin $I=1$ nuclei. The separation between the inner singularities is $116 \mathrm{kHz}$. The outer steps of the doublet are, however, not visible. With increasing temperature the evolution of a central component 

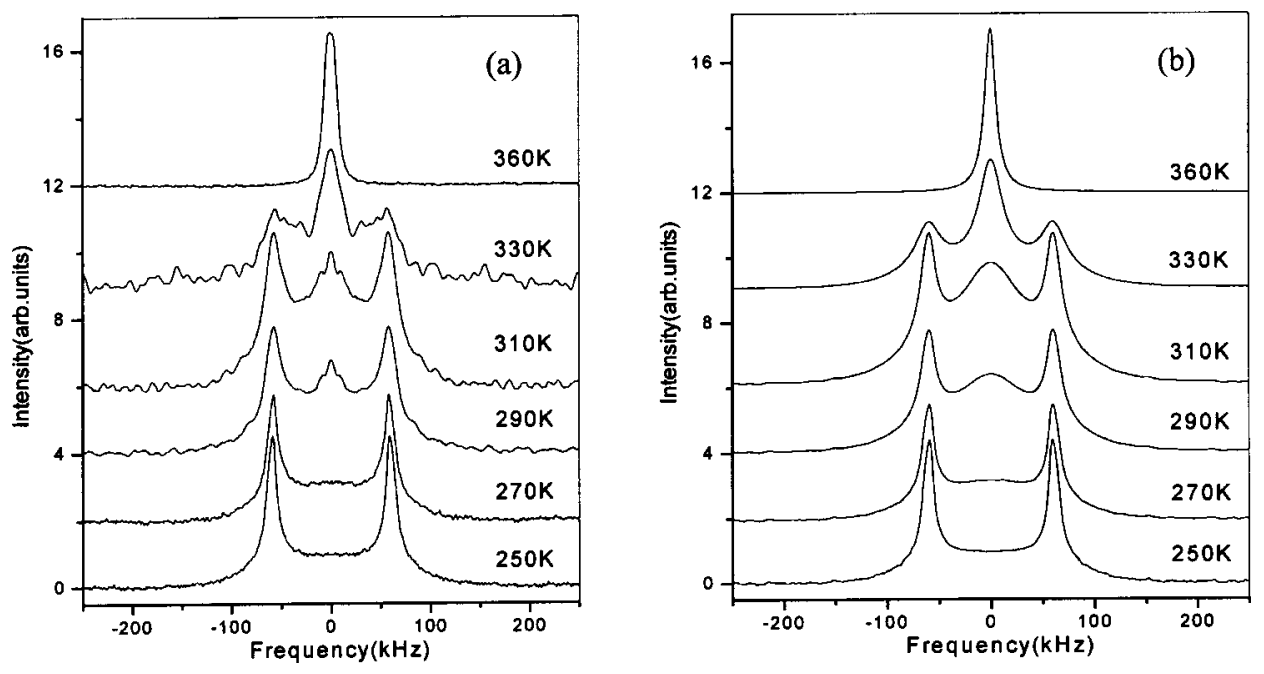

FIG. 3. (a) ${ }^{2} \mathrm{H}$ NMR spectra of $\mathrm{Cd}_{0.75} \mathrm{PS}_{3} \mathrm{Li}_{0.5}(\mathrm{PEO}-\mathrm{D})$ powder at different temperatures. (b) Fits to the experimental spectra. may clearly be seen in Fig. 3(a). This builds up in intensity with a concomitant decrease in the intensity of the quadrupolar doublet. There is, however, no change either in the position or separation of the doublet with temperature. Above $340 \mathrm{~K}$, only the central component is seen as a sharp line with a width [full width at half maximum (FWHM)] of $6.5 \mathrm{kHz}$.

${ }^{2} \mathrm{H}$ NMR has been widely used for studying molecular order and dynamics in polymeric systems. ${ }^{32}{ }^{2} \mathrm{H}$ NMR line shapes can provide information on the nature of motion and the associated time scales. In addition, motional heterogeneities if present can be detected and the associated distribution of correlation times directly determined. The ${ }^{2} \mathrm{H}$ NMR of the intercalated PEO in $\mathrm{Cd}_{0.75} \mathrm{PS}_{3} \mathrm{Li}_{0.5}\left(\mathrm{PEO}-{ }^{2} \mathrm{H}\right)$ is typical of many polymeric systems which show distinct spectral features for regions of grossly differing mobilities. ${ }^{32}$ The static powder pattern seen at low temperatures in the ${ }^{2} \mathrm{H}$ NMR spectrum of $\mathrm{Cd}_{0.75} \mathrm{PS}_{3} \mathrm{Li}_{0.5}\left(\mathrm{PEO}-{ }^{2} \mathrm{H}\right)$ corresponds to the rigid (immobile) segments of the intercalated PEO: the observed value of splitting $(116 \mathrm{kHz})$ is typical of rigid polymeric systems. ${ }^{32}$ The evolution of a central component with increasing temperature is due to the mobile polymer segments. It may be seen that the only change in the spectrum with increasing temperature is a reduction in intensity of the doublet with a concomitant increase in intensity at the center of the powder pattern; no change in the doublet separation is observed with temperature.

The intensities of the ${ }^{2} \mathrm{H}$ NMR spectral features reflect the equilibrium population of the rigid and mobile segments of the intercalated PEO. The spectra at any temperature would therefore be a superposition of a quadrupolar doublet due to the rigid fraction and a central component due to the more mobile segments of the intercalated PEO, with the weighted fractions directly proportional to their respective populations. The spectral line shapes have therefore been analyzed accordingly. This method is similar to the one used by Rössler $\mathrm{et} \mathrm{al.}^{33}$ to describe the temperature dependence of the ${ }^{2} \mathrm{H}$ NMR of deuterated benzene and hexamethylbenzene in organic glasses. The line shape at intermediate temperatures was considered as a weighted superposition of the spectra seen at the lowest and highest temperatures, correspond- ing to the rigid and mobile species, respectively.

The ${ }^{2} \mathrm{H}$ NMR spectra of $\mathrm{Cd}_{0.75} \mathrm{PS}_{3} \mathrm{Li}_{0.5}(\mathrm{PEO})$ was analyzed by considering the spectra at the lowest temperature $(250 \mathrm{~K})$ as representative of the rigid segments of the intercalated PEO and a Lorentzian, with variable linewidth at the center, as representative of the mobile fraction. The experimental spectra were fitted by floating the intensities of the two components and also the linewidth of the central Lorentzian. The fits to the experimental spectra [Fig. 3(a)] are shown in Fig. 3(b). A test of the above assumption that the intensities reflect the equilibrium population of the rigid and the mobile fractions of the polymer is to examine the temperature dependence of the logarithmic ratio of the intensities of the two components, $\ln \left(I_{\text {mobile }} / I_{\text {rigid }}\right)$; here, $I_{\text {mobile }}$ and $I_{\text {rigid }}$ are the intensities of the mobile and rigid fractions in the ${ }^{2} \mathrm{H}$ NMR [Fig. 3(a)]. This ratio would be directly proportional, if the above argument was valid, to the logarithmic ratio of the concentration of the mobile and rigid components, $\ln ([\mathrm{mobile}] /[$ rigid $])$. This ratio is the equilibrium constant $K$ and should follow the van't Hoff relation [Eq. (2)] if the assumption of equilibrium is correct:

$$
\frac{d \ln K}{d(1 / T)}=-\frac{\Delta H}{R} .
$$

In Fig. 4 the $\operatorname{logarithmic}$ ratio $\ln \left(I_{\text {mobile }} / I_{\text {rigid }}\right)$ has been plotted as a function of inverse temperature. The linearity of the plot clearly justifies the assumption of equilibrium, and the enthalpy as calculated from the linear slope is $4 \mathrm{kcal} / \mathrm{mol}$.

\section{B. ${ }^{7} \mathrm{Li} \mathrm{NMR}$ and motion of $\mathrm{Li}$ ions}

Lithium ion motion in the intercalated polymer electrolyte was probed using ${ }^{7} \mathrm{Li}$ NMR spectroscopy. The ${ }^{7} \mathrm{Li} \mathrm{NMR}$ spectra of $\mathrm{Cd}_{0.75} \mathrm{PS}_{3} \mathrm{Li}_{0.5}(\mathrm{PEO})$ powder at various temperatures are shown in Fig. 5. At the lowest temperature the spectrum consists of a broad line whose width decreases with increasing temperature. Although the spectra were recorded over a spectral width of $250 \mathrm{kHz}$, the $| \pm 3 / 2\rangle \leftrightarrow| \pm 1 / 2\rangle$ satellite transitions of the $I=3 / 2$ nucleus were not observed at temperatures below $330 \mathrm{~K}$. At temperatures above $330 \mathrm{~K}$, however, well-defined satellites may clearly be seen from 


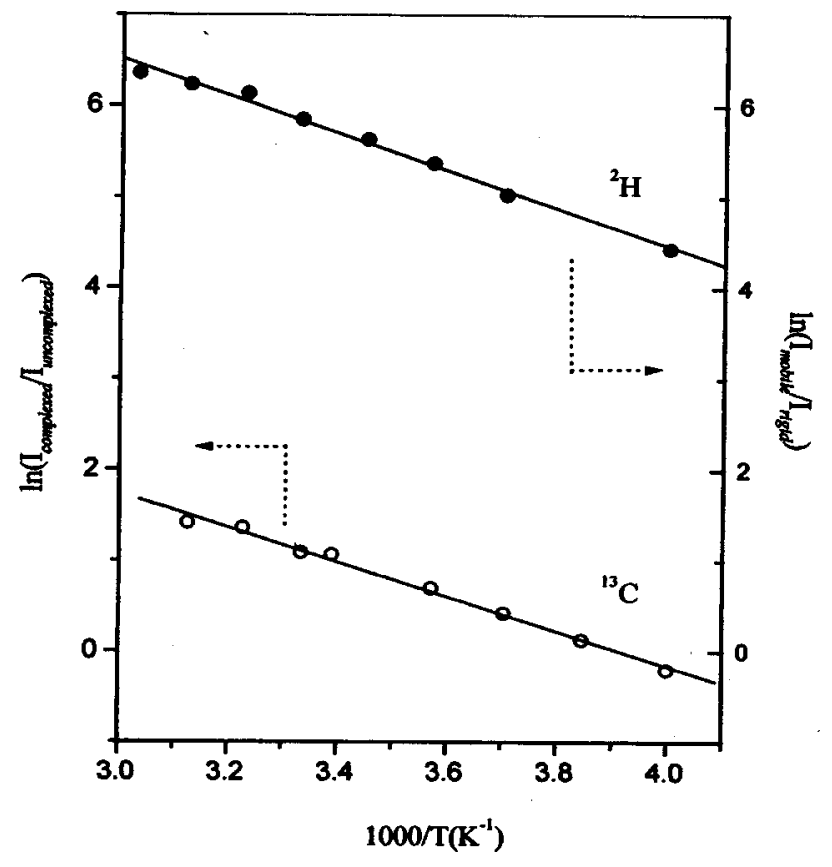

FIG. 4. Logarithmic ratio $\ln \left(I_{\text {mobile }} / I_{\text {rigid }}\right)$, obtained from the fits to the ${ }^{2} \mathrm{H}$ NMR, as a function of inverse temperature (shown as solid circles). The temperature variation of the ratio $\ln \left(I_{\text {complexed }} / I_{\text {uncomplexed }}\right)$ obtained from ${ }^{13} \mathrm{C}$ NMR is also shown (open circles). Solid lines are fits to the van't Hoff equation (2).

Fig. 5. The spectra in the temperature range 330-370 K resemble a static quadrupolar powder pattern expected for a $I$ $=3 / 2$ nucleus corresponding to an axial tensor ${ }^{34}$ and could be fitted to a theoretical powder pattern. ${ }^{35}$ In the temperature range $330-370 \mathrm{~K}$ the quadrupolar coupling constant $e^{2} q Q / h$ shows a linear increase with temperature.



FIG. 5. ${ }^{7} \mathrm{Li} \mathrm{NMR}$ spectra of $\mathrm{Cd}_{0.75} \mathrm{PS}_{3} \mathrm{Li}_{0.5}$ (PEO) powder at various temperatures.
The narrowing of the ${ }^{7} \mathrm{Li}$ spectra with increasing temperature from 200 to $330 \mathrm{~K}$ indicates an overall increase in mobility of $\mathrm{Li}$ ions and is in agreement with the conductivity data of $\mathrm{Cd}_{0.75} \mathrm{PS}_{3} \mathrm{Li}_{0.5}$ (PEO) (Fig. 2), which shows an enhancement of the conductivity values with temperature. The observation of a powder pattern with well-defined singularities corresponding to the satellite transitions $| \pm 3 / 2\rangle$ $\leftrightarrow| \pm 1 / 2\rangle$ at high temperatures $T>330 \mathrm{~K}$ is rather unusual. Neither the ${ }^{7} \mathrm{Li}$ linewidth nor the conductivity data (Fig. 2) show any evidence of change at this temperature. The narrow linewidth of the satellites and central component at $T$ $>330 \mathrm{~K}$ also suggests that all interlamellar $\mathrm{Li}$ ions are in almost identical environments at these temperatures. These observations appear to contradict the conductivity data, which show a high value of the dc conductivity at these temperatures. One would, therefore, expect the increased mobility of Li ions at higher temperatures to lead to more efficient averaging of dipolar and quadrupolar interactions. At these temperatures the ${ }^{2} \mathrm{H}$ NMR indicates that the intercalated polymer, too, is mobile. The conductivity data at high temperatures (250-370 K) (Fig. 2) clearly rule out any explanation based on localization of $\mathrm{Li}$ ions within or close to the $\mathrm{CdPS}_{3}$ layer. Localization of Li ions is also ruled out by the ac electrical response exhibited by $\mathrm{Cd}_{0.75} \mathrm{PS}_{3} \mathrm{Li}_{0.5}(\mathrm{PEO})$, which shows a well-defined conductivity relaxation in the electrical modulus while the corresponding dielectric spectra showed the absence of any loss feature due to the intercalated PEO. This was interpreted as evidence for the coupling of ionic motion with polymer motion. Such a coupling would not be possible if $\mathrm{Li}$ ions were localized in the layer. Thus a mechanism of Li ion motion consistent with both conductivity and NMR results needs to be found.

In analyzing the ${ }^{7} \mathrm{Li}$ NMR spectra for $T>330 \mathrm{~K}$ (Fig. 5) it may be emphasized that ionic ${ }^{7} \mathrm{Li}$ has no field gradient associated with its own electrons as the $1 s$ orbitals do not participate in bonding and are spherically symmetric. The magnitude of the quadrupolar interactions is therefore a probe of the distribution of charges in the immediate neighborhood of the ion. The ${ }^{7} \mathrm{Li} \mathrm{NMR}$ spectrum would therefore reflect the time average of the interaction of the nuclear quadrupole moment with a charge distribution in the neighborhood of the ion. In $\mathrm{Cd}_{0.75} \mathrm{PS}_{3} \mathrm{Li}_{0.5}(\mathrm{PEO})$, since magnetic interactions of $\mathrm{Li}$ ions with the layer may be ruled out, the field gradient at the ${ }^{7} \mathrm{Li}$ nuclei would be derived primarily from the ether oxygens of the intercalated PEO, which are expected to solvate the Li ion. The observation of quadrupolar satellites for $T>330 \mathrm{~K}$ is therefore a clear indication of the association or complexation of the $\mathrm{Li}$ ion by the intercalated PEO. The spectra at $T>330 \mathrm{~K}$, in fact, bear a striking resemblance to that of the ${ }^{7} \mathrm{Li} \mathrm{NMR}$ spectra reported for Li-crown-ether complexes. ${ }^{32}$ The ${ }^{2} \mathrm{H}$ NMR results had, however, indicated the presence of mobile segments of the intercalated PEO at these temperatures. The appearance of quadrupolar satellites in the ${ }^{7} \mathrm{Li} \mathrm{NMR}$ at high temperatures in conjunction with the ${ }^{2} \mathrm{H}$ NMR results, therefore, implies that the complexation of Li ions are by mobile segments of the intercalated PEO. The lifetime of this associated or quasibound state would have to be longer than the inverse of the 
observed quadrupolar splitting $\left(\sim 10^{-4} \mathrm{~s}\right)$; a shorter lifetime would destroy the structure.

In comparing these results with the conductivity data it may be emphasized that the ${ }^{7} \mathrm{Li}$ NMR spectroscopy probes the environment and motion of $\mathrm{Li}$ ions in the polymer's frame of reference, either through heteronuclear dipolar or quadrupolar interactions. The conductivity measurements in contrast sense $\mathrm{Li}$ ion motion from the laboratory frame. The observed powder pattern in the ${ }^{7} \mathrm{Li} \mathrm{NMR}$, therefore, does not imply that $\mathrm{Li}$ ions are static in the laboratory frame, but static on time scales greater than the quadrupolar splitting, in the polymer's frame of reference: i.e., the $\mathrm{Li}$ ion stays bound to the mobile polymer for times of the order of $10^{-4} \mathrm{~s}$. The association of $\mathrm{Li}$ ions with mobile segments of the intercalated PEO can therefore explain the observation of quadrupolar satellites at high temperatures as well as enhanced $\mathrm{Li}$ ion mobility indicated by the conductivity data (Fig. 2) at these temperatures. ${ }^{7}$

The observation of quadrupolar splitting at $T>330 \mathrm{~K}$ and the fact that it shows a linear increase with temperature is similar to the behavior observed in the ${ }^{7} \mathrm{Li} \mathrm{NMR}$ of $\mathrm{Li}-$ crown-ether complexes. ${ }^{36}$ In 12-crown-4-lithium chloride, too, no quadrupolar splitting is observed at low temperatures, but on raising the temperature quadrupolar satellites corresponding to the $| \pm 3 / 2\rangle \leftrightarrow| \pm 1 / 2\rangle$ transitions are seen with the quadrupole coupling constant reaching a value of $\sim 67$ $\mathrm{kHz}$ at $360 \mathrm{~K}^{36}$ In fact, a number of $\mathrm{Li}$ compounds have been reported to show an increased ${ }^{7} \mathrm{Li}$ quadrupolar splitting with temperature and this appears to be characteristic feature of light quadrupolar nuclei. ${ }^{37}$ This temperature dependence has been explained as a consequence of the fact that the quadrupolar coupling constant is determined by the timeaveraged electric field gradient (efg) sampled by the ${ }^{7} \mathrm{Li}$ nuclei. These gradients vary in the region of space around the $\mathrm{Li}$ ion; the magnitude of the time average depends on the shape and extent of the region in which the nucleus moves. Thus anisotropic motion and oscillation of the Li nucleus would give rise to an efg whose magnitude would depend on the anisotropy of the root mean square of the amplitude. An increase in the latter quantity with temperature would lead to an increase in the quadrupolar coupling. ${ }^{37}$ Indeed, an Einstein oscillator model for such a motion predicts a linear increase in the quadrupolar coupling with temperature ${ }^{35,37}$ a more detailed analysis of the origin and temperature dependence of the quadrupolar coupling in $\mathrm{Cd}_{0.75} \mathrm{PS}_{3} \mathrm{Li}_{0.5}(\mathrm{PEO})$ is presented in the following paper]. ${ }^{38}$

The linewidth (FWHM) of the central $(1 / 2 \leftrightarrow-1 / 2)$ transition of the experimental ${ }^{7} \mathrm{Li}$ spectra of $\mathrm{Cd}_{0.75} \mathrm{PS}_{3} \mathrm{Li}_{0.5}(\mathrm{PEO})$ has been plotted as a function of temperature in Fig. 6. Two regions may be clearly seen in Fig. 6, indicating a change in the mechanism of line narrowing at $\sim 260 \mathrm{~K}$. It may be recalled that the conductivity data (Fig. 2) of $\mathrm{Cd}_{0.75} \mathrm{PS}_{3} \mathrm{Li}_{0.5}(\mathrm{PEO})$, too, shows a change in the mechanism of conduction with temperature. ${ }^{7}$ The variation of the ${ }^{7} \mathrm{Li}$ NMR linewidths in the two regions were analyzed by relating the linewidth $\Delta \omega$ to a correlation time $\tau_{d}$ by the phenomenological relation ${ }^{34}$

$$
\Delta \omega^{2}=\Delta \omega_{\mathrm{HT}}^{2}+(2 / \pi) \Delta \omega_{\mathrm{RL}}^{2} \arctan \left(\alpha \Delta \omega \tau_{d}\right),
$$

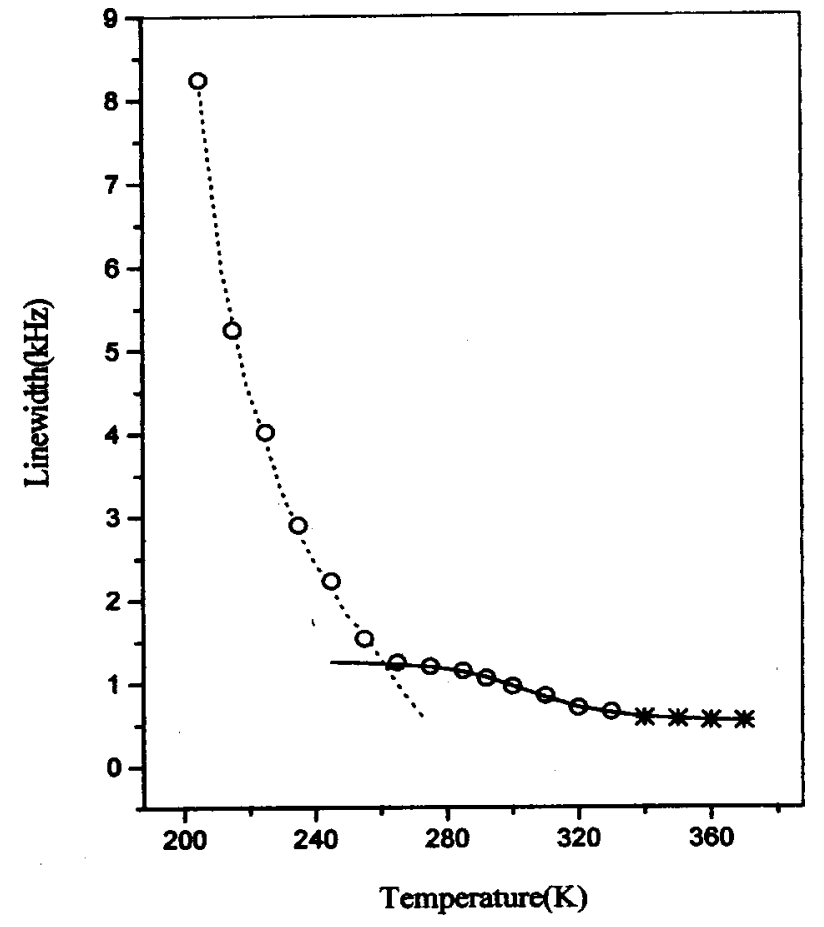

FIG. 6. Linewidth of ${ }^{7} \mathrm{Li}$ NMR spectra of $\mathrm{Cd}_{0.75} \mathrm{PS}_{3} \mathrm{Li}_{0.5}(\mathrm{PEO})$ as a function of temperature. At temperatures above $330 \mathrm{~K}$ the linewidth is that of the central $|1 / 2\rangle \leftrightarrow|-1 / 2\rangle$ component (marked by stars). The Arrhenius fit to the low-temperature data is shown as a dotted line, while the VTF fit as the solid line.

where the numerical factor $\alpha$ is of order unity. $\Delta \omega_{\mathrm{HT}}$ is the high-temperature limiting linewidth and $\Delta \omega_{\mathrm{RL}}$ the rigid lattice linewidth. Equation (3) was fitted to the experimental data of Fig. 6 by floating the values of $\Delta \omega_{\mathrm{HT}}$ and $\Delta \omega_{\mathrm{RL}}$. In the temperature range $200-265 \mathrm{~K}$, where the linewidth drops sharply, the best fit was obtained assuming $\tau_{d}$ had an Arrhenius temperature dependence:

$$
\tau_{d}=\tau_{0} e^{E_{a} / k T} .
$$

The dotted line in Fig. 6 shows the fit for data below $265 \mathrm{~K}$ : $\tau_{0}=2.3 \times 10^{-6} \mathrm{~s}$ and $E_{a}=3.6 \mathrm{kcal} / \mathrm{mol}$. For temperatures above $265 \mathrm{~K}$ the best fits were obtained assuming a VTF-like temperature dependence of the correlation time $\tau_{d}$ :

$$
\tau_{d}=\tau_{0} T^{-1 / 2} e^{B /\left(T-T_{0}\right)} .
$$

In the above expression $B$ is a pseudoactivation energy and $T_{0}$ the equilibrium glass transition temperature. The fit, solid line in Fig. 6, is for $\tau_{0}=3.4 \times 10^{-4} \mathrm{~s}, B=2.4 \mathrm{kcal} / \mathrm{mol}$, and $T_{0}=81.1 \mathrm{~K}$.

It is interesting to note that the value of $T_{0}$ in the VTF expression, which in polymeric systems may be interpreted as the temperature at which all segmental motions are frozen, obtained from a fit of the NMR data, $81 \mathrm{~K}$, is close to the value obtained from the conductivity data, $90.7 \mathrm{~K}^{7}$ The value of the kinetic parameters $E_{a}$ and $B$ as well as the temperature at which the crossover in mechanism occurs is, of course, different for the NMR and dc conductivity since the time scales associated with these measurements are different.

In the intercalated polymer electrolytes where both cation and polymer motions are present the question as to the dynamics of which species is being probed by the ${ }^{7} \mathrm{Li}$ NMR 
linewidth has to be answered with care, since either of these motions could average out $\mathrm{Li}$-polymer interactions leading to a narrowing of the linewidth. At low temperatures it is clearly that of the Li ion since the ${ }^{2} \mathrm{H}$ NMR indicates the absence of polymer motion at these temperatures. In this temperature regime it is the classical Arrhenius hopping of $\mathrm{Li}$ ions which averages out the $\mathrm{Li}-\mathrm{PEO}$ interactions (since the linewidths in Fig. 6 are of the central transition these interactions would be primarily ${ }^{1} \mathrm{H}-{ }^{7} \mathrm{Li}$ dipolar interactions). At temperatures above $265 \mathrm{~K}$ both Li ion motion and polymer segmental motion are present. Rigid as well as mobile segments of the intercalated PEO are present at these temperatures. In the intercalated polymer electrolytes $\mathrm{Cd}_{0.75} \mathrm{PS}_{3} A_{0.5}(\mathrm{PEO}) \quad(A=\mathrm{K}, \mathrm{Cs}) \quad$ where conductivity and polymer segmental relaxations are decoupled and the hightemperature dc ionic conductivity remains Arrhenius, it is known that polymer segmental motion is faster than the classical ion hopping rates and has a VTF temperature dependence. ${ }^{6,7}$ In such a situation the alkali ion NMR would reflect the dynamics of the faster species-i.e., the polymer. Such a model for the temperature dependence of the ${ }^{7} \mathrm{Li}$ NMR in $\mathrm{Cd}_{0.75} \mathrm{PS}_{3} \mathrm{Li}_{0.5}(\mathrm{PEO})$ is, however, inappropriate because the narrowing of the ${ }^{7} \mathrm{Li}$ linewidth for $T>265 \mathrm{~K}$ is more gradual as compared to that for temperatures below $265 \mathrm{~K}$. This implies that the motions of the two species are correlated. If the motions of the Li ion and mobile segments of the interlamellar PEO were uncorrelated, then a steeper narrowing of the linewidth would be expected at higher temperatures, contrary to what is observed. The observation of Li quadrupolar splitting at high temperature provides further evidence of the association of $\mathrm{Li}$ ions with mobile polymer segments. These observations provide direct spectroscopic evidence of the association of $\mathrm{Li}$ ions with mobile segments of the intercalated PEO. The Li ion mobility would show a similar temperature dependence as the mobile segments of the intercalated PEO with which it is associated. In the $\mathrm{CdPS}_{3}$-based alkali ion intercalated polymer electrolytes it is known from dielectric relaxation studies ${ }^{6,7}$ that polymer segmental relaxation rates follow a VTF temperature dependence and hence the mobilities of the Li ions, too, show a similar temperature dependence.

In the following section we look for further evidence of this association by examining the ${ }^{13} \mathrm{C} \mathrm{NMR}$ as well as IR spectra as a function of temperature.

\section{C. ${ }^{13} \mathrm{C}$ NMR}

The temperature variation of ${ }^{13} \mathrm{C}$ NMR spectra of $\mathrm{Cd}_{0.75} \mathrm{PS}_{3} \mathrm{Li}_{0.5}(\mathrm{PEO})$ powder is shown in Fig. 7. At low temperatures the ${ }^{13} \mathrm{C}$ NMR spectra show two features at 3.1 and $6.3 \mathrm{kHz}$, respectively. With increasing temperature the feature at $6.3 \mathrm{kHz}$ grows in intensity at the expense of the feature at $3.1 \mathrm{kHz}$. These features may be assigned to ${ }^{13} \mathrm{C}$ nuclei with differing chemical shifts. The feature appearing at 6.3 $\mathrm{kHz}$ may be assigned to PEO segments complexing the $\mathrm{Li}$ ion while that at $3.1 \mathrm{kHz}$ to uncomplexed PEO. This assignment is based on the fact that complexation of the positive $\mathrm{Li}$ ion would lead to a deshielding of the methylene carbons and, hence, a downfield shift with respect to methylene car-



FIG. 7. ${ }^{13} \mathrm{C}$ NMR spectra of $\mathrm{Cd}_{0.75} \mathrm{PS}_{3} \mathrm{Li}_{0.5}(\mathrm{PEO})$ as a function of temperature along with the fit.

bons of the uncomplexed PEO. The variation in the intensities of the features at 3.1 and $6.3 \mathrm{kHz}$ with temperature would therefore indicate the change in the equilibrium population of the complexed and uncomplexed PEO segments. The spectra have been analyzed accordingly. The spectra at any temperature would be a linear combination of the spectra of the complexed PEO and the uncomplexed PEO with the weighting fractions proportional to the respective populations. This method is similar to that used in the analysis of the ${ }^{2} \mathrm{H}$ spectra.

The experimental spectrum at all temperatures could be fitted to two Lorentzians (Fig. 7). If the assumption that the complexed fraction, the peak at $6.3 \mathrm{kHz}$, and uncomplexed fraction, the peak at $3.1 \mathrm{kHz}$, are in equilibrium is true, then the temperature dependence of the logarithmic ratio of the integrated intensities of the two components should follow the van 't Hoff relation [Eq. (2)]. In Fig. 4 the logarithmic ratio $\ln \left(I_{\text {complexed }} / I_{\text {uncomplexed }}\right)$, obtained from the fits to the ${ }^{13} \mathrm{C}$ NMR, has been plotted as a function of inverse temperature. The linearity of plot (Fig. 4) clearly justifies the assumption of equilibrium, and the enthalpy as calculated from the linear slope is $3.8 \mathrm{kcal} / \mathrm{mol}$. The temperature variation of the logarithmic ratio of the mobile to rigid fraction, $\ln \left(I_{\text {mobile }} / I_{\text {rigid }}\right)$, obtained from the ${ }^{2} \mathrm{H}$ NMR, is also shown in Fig. 4. The interesting feature is that the slopes of the two are nearly identical; the enthalpies calculated from the linear slopes of both the ${ }^{13} \mathrm{C}(4 \mathrm{kcal} / \mathrm{mol})$ and ${ }^{2} \mathrm{H}$ NMR $(3.8 \mathrm{kcal} /$ mol) data are close. Figure 4 indicates that the thermal parameters describing the equilibrium between complexed PEO and uncomplexed PEO are same as those between mobile and rigid fractions of PEO and further corroborates the previous conclusion that $\mathrm{Li}$ ions are associated and complexed only by the mobile polymer segments.

\section{IR spectroscopy}

Vibrational spectroscopy is a powerful tool for probing association and complexation of $\mathrm{Li}$ ions by polyethers. ${ }^{39}$ If 

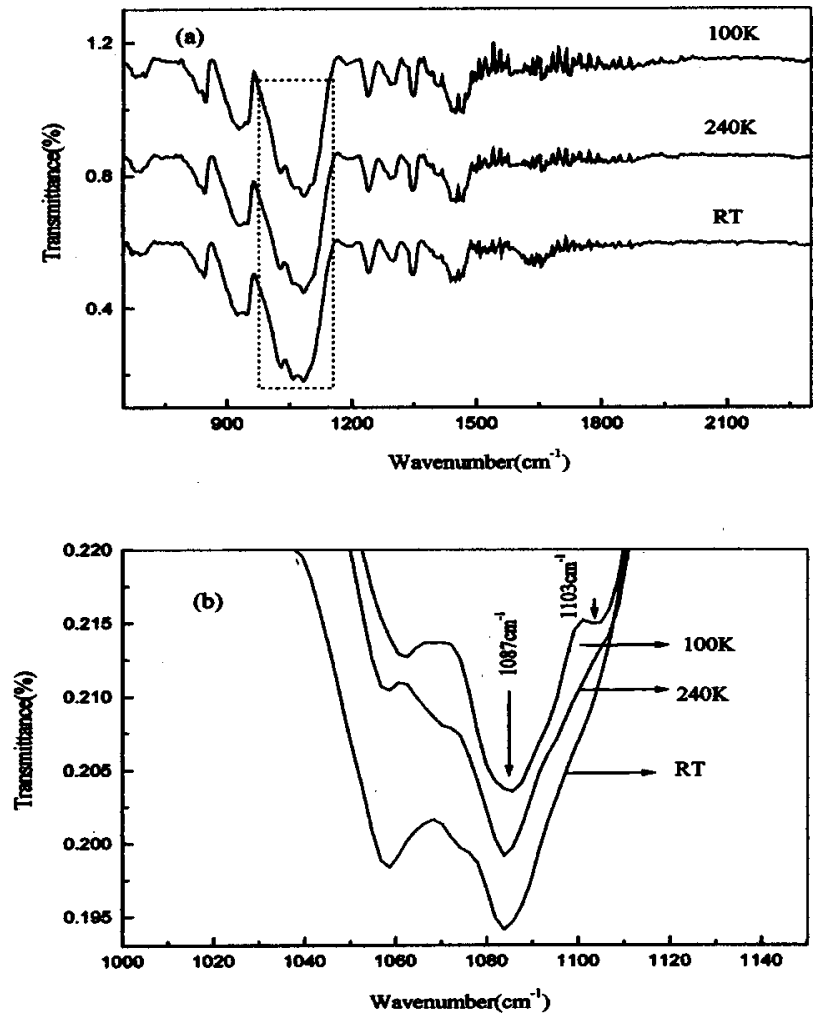

FIG. 8. (a) Mid-IR spectra of $\mathrm{Cd}_{0.75} \mathrm{PS}_{3} \mathrm{Li}_{0.5}$ ( $\mathrm{PEO}$ ) powder as a function of temperature. (b) Magnified view of the $1100 \mathrm{~cm}^{-1}$ region [the boxed region in (a)].

$\mathrm{Li}$ ions are coordinated to the ether oxygens, then changes in the vibrational modes involving the ether oxygens-the $\mathrm{C}-\mathrm{O}-\mathrm{C}$ stretching and bending modes-may be anticipated. In SPEs such changes have indeed been observed. In pure PEO the $\mathrm{C}-\mathrm{O}-\mathrm{C}$ stretching mode appears as a strong band at $1105 \mathrm{~cm}^{-1}$ whereas in the SPEs this band appears at lower wave numbers, the value of which depends on the alkali ion. ${ }^{39}$ For the PEO-NaSCN SPE this band appears at 1087 $\mathrm{cm}^{-1}$. In a previous study ${ }^{5}$ of the room-temperature infrared spectra of $\mathrm{Cd}_{0.75} \mathrm{PS}_{3} \mathrm{Li}_{0.5}(\mathrm{PEO})(A=\mathrm{Li}, \mathrm{Na}, \mathrm{K}, \mathrm{Cs})$ the positions of the $\mathrm{C}-\mathrm{O}-\mathrm{C}$ stretching bands for the $\mathrm{Na}$ and $\mathrm{Li}$ compounds were found to have shifted to lower wave numbers and interpreted as evidence for the association of $\mathrm{Li}$ ions with the ether oxygens of the intercalated PEO.

The mid-IR spectra of $\mathrm{Cd}_{0.75} \mathrm{PS}_{3} \mathrm{Li}_{0.5}(\mathrm{PEO})$ at representative temperatures is shown in Fig. $8(\mathrm{a})$. The $1100-\mathrm{cm}^{-1}$ region where changes are expected is shown in greater detail in Fig. 8(b). At room temperature the IR spectra of $\mathrm{Cd}_{0.75} \mathrm{PS}_{3} \mathrm{Li}_{0.5}(\mathrm{PEO})$ show a strong band at $1087 \mathrm{~cm}^{-1}$ : this is assigned to the $\mathrm{C}-\mathrm{O}-\mathrm{C}$ stretching modes of ether linkages coordinated to $\mathrm{Li}$ ions. On lowering the temperature a shoulder appears at $\sim 1103 \mathrm{~cm}^{-1}$, which is clearly resolved by 100 $\mathrm{K}$. The position of this band is identical to that of pure PEO and suggests dissociation of the Li-ion-PEO complex on lowering the temperature.

It is known from ${ }^{2} \mathrm{H}$ NMR that at high temperatures the polymer is mobile but at low temperature rigid. The IR spectrum therefore indicates that coordination of the $\mathrm{Li}$ ions is only by the ether linkages of mobile PEO segments but once polymer motion is frozen the $\mathrm{Li}$ ions are no longer coordi- nated with the ether oxygens. This result is in agreement with the observation of the previous section where a similar conclusion had been drawn from a comparison of the temperature dependence of the ratios of the complexed and uncomplexed fraction in the ${ }^{13} \mathrm{C}$ NMR with the ratios of the mobile and rigid fraction in the ${ }^{2} \mathrm{H}$ NMR.

\section{CONCLUSION}

The motions of $\mathrm{Li}$ ions and interlamellar PEO in the intercalated polymer electrolyte $\mathrm{Cd}_{0.75} \mathrm{PS}_{3} \mathrm{Li}_{0.5}(\mathrm{PEO})$ have been investigated using a combination of multinuclear NMR and IR spectroscopy. The main observations of the present study are summarized below.

(i) ${ }^{2} \mathrm{H}$ NMR results indicate the presence of both rigid and mobile fractions of the intercalated PEO with the equilibrium concentration of the mobile fraction increasing with temperature.

(ii) ${ }^{7} \mathrm{Li}$ NMR spectra in the temperature range $230-330$ $\mathrm{K}$ show a single line whose width decreases with increasing temperature. Above $330 \mathrm{~K}$ well-defined singularities corresponding to the satellite transitions $| \pm 3 / 2\rangle \leftrightarrow| \pm 1 / 2\rangle$ are observed.

(iii) The temperature variation of the linewidth of the central transition in the ${ }^{7} \mathrm{Li}$ NMR shows clear evidence of a change in the mechanism of motional narrowing at $260 \mathrm{~K}$. Below $260 \mathrm{~K}$ the correlation time associated with this motion has an Arrhenius temperature dependence, but above $260 \mathrm{~K}$ has a VTF temperature dependence. The variation of the ${ }^{7} \mathrm{Li}$ linewidth with temperature is similar to the temperature dependence observed for the dc conductivity. The VTF $T_{0}$ value, which may be interpreted as the temperature below which segmental motion freezes, obtained from fitting the ${ }^{7} \mathrm{Li}$ linewidth data $(81.1 \mathrm{~K})$, is close to the value obtained from the conductivity data $(90.7 \mathrm{~K})$.

(iv) The ${ }^{7} \mathrm{Li}$ NMR spectra exhibit a quadrupolar powder pattern above $330 \mathrm{~K}$ with the quadrupole coupling constant increasing linearly with temperature. This behavior is similar to that observed in $\mathrm{Li}$-crown-ether complexes where too quadrupolar splitting is observed only above a certain temperature, increasing with a further rise in temperature. Above $330 \mathrm{~K}$ a significant fraction of the intercalated PEO is mobile and therefore the observation of a quadrupolar splitting in ${ }^{7} \mathrm{Li}$ NMR spectra at these temperatures indicates that the association of $\mathrm{Li}$ ions is with ether oxygen of the mobile PEO segments.

(v) The ${ }^{13} \mathrm{C}$ NMR spectra show two features at low temperatures, corresponding to complexed and uncomplexed PEO segments. The intensity of the complexed fraction increases with temperature. The thermal parameters describing the equilibrium between complexed and uncomplexed PEO, obtained from the ${ }^{13} \mathrm{C}$ NMR spectra, is similar to that between mobile and rigid fractions of interlamellar PEO, obtained from ${ }^{2} \mathrm{H}$ NMR measurements, implying that complexation of $\mathrm{Li}$ ions is by mobile segments of the intercalated PEO.

(vi) At room temperature the frequency of the $\mathrm{C}-\mathrm{O}-\mathrm{C}$ stretching mode $\left(1087 \mathrm{~cm}^{-1}\right)$ in the IR spectrum indicates the coordination of $\mathrm{Li}$ ions by the ether linkages of the interlamellar PEO. At low temperatures the appearance of a spec- 
tral feature $\left(1103 \mathrm{~cm}^{-1}\right)$ identical to that of pure PEO indicates the presence of ether linkages which are no longer coordinated to $\mathrm{Li}$ ions.

From these observations it is possible to establish that in the intercalated polymer electrolyte $\mathrm{Cd}_{0.75} \mathrm{PS}_{3} \mathrm{Li}_{0.5}(\mathrm{PEO}), \mathrm{Li}$ ions are complexed by mobile segments of the intercalated PEO which are present at higher temperatures. The complexation of $\mathrm{Li}$ ions by the ether linkages of the intercalated PEO would be enthalpically favorable at all temperatures. At low temperatures, however, when the intercalated PEO segments are frozen, polymer configurations which are favorable for $\mathrm{Li}$ ion complexation may not be available. Moreover, at low temperatures, when the polymer is rigid association of $\mathrm{Li}$ ions with rigid PEO segments would be entropically unfavorable. The barrier for hopping for the small $\mathrm{Li}$ ion is small so that the enthalpy gain by complexation would not compensate for the loss of entropy. In such situations the Li ion exhibits the conventional classical hopping giving rise to the Arrhenius temperature-dependent conductivity observed in the intercalated polymer electrolytes at low temperatures. ${ }^{7}$ In other words, the motion of the Li ion is dissociated from that of the rigid polymer and moves independently.

At higher temperatures, however, when the intercalated polymer too is mobile, polymer configurations which can complex the $\mathrm{Li}$ ion would be available. Association of the $\mathrm{Li}$ ions with the mobile PEO would be both entropically and enthalpically favorable, especially since the polymer reorientation rates are faster than the classical hopping rates. The present NMR and IR studies provide direct spectroscopic evidence for this association. The quadrupolar splitting of $\sim 10 \mathrm{kHz}$ in the ${ }^{7} \mathrm{Li} \mathrm{NMR}$ of $\mathrm{Cd}_{0.75} \mathrm{PS}_{3} \mathrm{Li}_{0.5}$ (PEO) indicates that the lifetime of the associated or quasibound state for the $\mathrm{Li}$ ion must be greater than $10^{-4} \mathrm{~s}$. The displacement of the $\mathrm{Li}$ ion during this period would be described by the VTF temperature dependence since the polymer segments with which it is "bound" show this dependence. ${ }^{7}$

$\mathrm{Li}$ ion transport requires that the ion be able to move from one quasibound site to another. This would require breaking of the polyether oxygen-Li linkages with subsequent attachment to a different set of polyether oxygens. The ${ }^{7} \mathrm{Li}$ NMR, however, does not show any signature of this transitory process, which suggests that the lifetime of these states-i.e., between two quasibound events-must be very small $\left(\tau \ll 1 / \omega_{\text {Larmor }}, \omega_{\text {Larmor }}=116.4 \mathrm{MHz}\right)$. Indeed, molecular dynamics simulations of PEO-based solid polymer electrolytes have observed that dynamical changes in the crownether-like coordination shell of the alkali ion occurs in 1001000 ps regime. ${ }^{40}$ The picture that emerges is that of quasibound motion of the $\mathrm{Li}$ ion with an occasional shortlived process involving detachment of the $\mathrm{Li}$ ion from one set of ether oxygens and attachment to a different set. A set of breakings and attachment could eventually lead to displacement of the Li ion over macroscopic distances. Significant displacement of the $\mathrm{Li}$ ion probably occurs in the longlived quasibound state of the ion with mobile PEO segments. The mobility of the ion therefore shows a similar temperature dependence (VTF) as the polymer segments with which it is associated. The present results provide direct spectroscopic evidence of the quasibound state involving association of $\mathrm{Li}$ ions with mobile segments of the interlamellar PEO.

${ }^{1}$ E. P. Gianellis, R. Krishnamoorti, and E. Manias, in Advances in Polymer Science, edited by S. Granick, (Springer-Verlag, Berlin, 1999), Vol. 138, p. 107.

${ }^{2}$ E. Ruiz-Hitzky, Adv. Mater. (Weinheim, Ger.) 5, 334 (1993).

${ }^{3}$ P. Jeevanandam and S. Vasudevan, J. Phys. Chem. B 102, 5753 (1998).

${ }^{4}$ N. Arun, S. Vasudevan, and K. V. Ramanathan, J. Am. Chem. Soc. 122, 6028 (2000).

${ }^{5}$ P. Jeevanandam and S. Vasudevan, Chem. Mater. 10, 1276 (1998).

${ }^{6}$ P. Jeevanandam and S. Vasudevan, J. Chem. Phys. 109, 8102 (1998).

${ }^{7}$ P. Jeevanandam and S. Vasudevan, J. Chem. Phys. 109, 8109 (1998).

${ }^{8}$ P. V. Wright, Br. Polym. J. 7, 319 (1975).

${ }^{9}$ Polymer Electrolyte Reviews, edited by J. R. MacCallum and C. A. Vincent (Elsevier, New York, 1987 and 1989), Vols. 1 and 2.

${ }^{10}$ Solid State Electrochemistry, edited by P. G. Bruce (Cambridge University Press, Cambridge, England, 1995).

${ }^{11}$ D. F. Shriver and P. G. Bruce, in Solid State Electrochemistry, edited by P. G. Bruce (Cambridge University Press, Cambridge, England, 1995).

${ }^{12}$ M. B. Armand, in Polymer Electrolyte Reviews, edited by J. R. MacCallum and C. A. Vincent (Elsevier, London, 1987), Vol. 1.

${ }^{13}$ W. Gorecki, B. Belorizky, C. Berthier, P. Donoso, and M. Armand, Electrochim. Acta 37, 1685 (1992).

${ }^{14}$ J. P. Donoso, T. J. Bonagamba, H. C. Panepucci, and L. N. Oliveira, J. Chem. Phys. 98, 10026 (1993).

${ }^{15}$ M. A. Ratner, in Polymer Electrolyte Reviews, edited by J. R. MacCallum and C. A. Vincent (Elsevier, London, 1987), Vol. 1.

${ }^{16}$ C. R. A. Catlow, A. V. Chadwick, G. N. Greaves, L. Moroney, and M. R. Worboys, Solid State Ionics 91, 1107 (1993)

${ }^{17}$ P. Lightfoot, M. A. Mehta, and P. G. Bruce, Science 262, 883 (1993).

${ }^{18}$ G. S. MacGlashan, Y. G. Andreev, and P. G. Bruce, Nature (London) 398, 792 (1999).

${ }^{19}$ P. G. Bruce and F. M. Gray, in Solid State Electrochemistry, edited by P. G. Bruce (Cambridge University Press, Cambridge, England, 1995).

${ }^{20}$ A. Ferry, P. Jacobson, and L. M. Torell, Electrochim. Acta 40, 2369 (1995).

${ }^{21}$ A. Ferry, J. Phys. Chem. B 101, 150 (1997).

${ }^{22}$ D. Fauteux, M. D. Lupien, and C. D. Robitaille, J. Electrochem. Soc. 134, 2761 (1987).

${ }^{23}$ N. Arun, S. Vasudevan, and K. V. Ramanathan, J. Phys. Chem. B 104, 9091 (2000).

${ }^{24}$ S. H. Chung, K. R. Jeffrey, and J. R. Stevens, J. Chem. Phys. 94, 1803 (1991).

${ }^{25}$ S. H. Chung, K. R. Jeffrey, and J. R. Stevens, Phys. Rev. B 51, 2826 (1995).

${ }^{26}$ S. Wong, S. Vasudevan, R. A. Vaia, E. P. Giannelis, and D. B. Zax, J. Am. Chem. Soc. 117, 7568 (1995).

${ }^{27}$ S. Wong, R. A. Vaia, E. P. Giannelis, and D. B. Zax, Solid State Ionics 86-88, 547 (1996).

${ }^{28}$ D. K. Yang and D. B. Zax, J. Chem. Phys. 110, 5325 (1999).

${ }^{29}$ W. Klingen, R. Ott, and H. Hahn, Z. Anorg. Allg. Chem. 396, 271 (1973).

${ }^{30}$ G. Ouvrard, R. Brec, and J. Rouxel, Mater. Res. Bull. 20, 1181 (1985).

${ }^{31}$ P. Jeevanandam and S. Vasudevan, Solid State Ionics 104, 45 (1997).

${ }^{32}$ H. W. Spiess, Advances in Polymer Science (Springer-Verlag, Berlin, 1985), Vol. 66, pp. 23-58.

${ }^{33}$ E. Rössler, M. Taupitz, K. Börner, M. Schulz, and H. M. Vieth, J. Chem. Phys. 92, 5847 (1990).

${ }^{34}$ A. Abragam, Principles of Nuclear Magnetism (Oxford University Press, London, 1961).

${ }^{35}$ N. Arun, Ph.D thesis, Indian Institute of Science, Bangalore, India, 2001.

${ }^{36}$ T. Pietrass and P. K. Burkert, Magn. Reson. Chem. 31, 709 (1993).

${ }^{37}$ T. K. Halstead, J. Chem. Phys. 53, 3427 (1970).

${ }^{38}$ N. Arun, S. Vasudevan, and K. V. Ramanathan, J. Chem. Phys. 119, 2849 (2000), following paper.

${ }^{39}$ B. L. Papke, M. A. Ratner, and D. F. Shriver, J. Phys. Chem. Solids 42, 493 (1981).

${ }^{40}$ S. Neyertz and D. Brown, J. Chem. Phys. 104, 3797 (1996). 